\title{
Effects of Concentration of Organically Modified Nanoclay on Properties of Sulfonated Poly(vinyl alcohol) Nanocomposite Membranes
}

\author{
Apiradee Sanglimsuwan, ${ }^{1}$ Narumon Seeponkai, ${ }^{2}$ and Jatuphorn Wootthikanokkhan ${ }^{2}$ \\ ${ }^{1}$ Department of Chemical Engineering, Massachusetts Institute of Technology, Cambridge, MA 02139, USA \\ ${ }^{2}$ Divison of Materials Technology, School of Energy, Environment and Materials, King Mongkut's University of Technology Thonburi, \\ Bangkok 10140, Thailand
}

Correspondence should be addressed to Jatuphorn Wootthikanokkhan, jatuphorn.woo@kmutt.ac.th

Received 7 March 2011; Accepted 1 April 2011

Academic Editor: Shuangyin Wang

Copyright (C) 2011 Apiradee Sanglimsuwan et al. This is an open access article distributed under the Creative Commons Attribution License, which permits unrestricted use, distribution, and reproduction in any medium, provided the original work is properly cited.

\begin{abstract}
Electrolyte nanocomposite membranes for proton exchange membrane fuel cells and direct methanol fuel cells were prepared by carrying out a sulfonation of poly(vinyl alcohol) with sulfosuccinic acid and adding a type of organically modified montmorillonite (layered silicate nanoclay) commercially known as Cloisite 93A. The effects of the different concentrations (0, 2, 4, 6, 8 wt. \%) of the organoclay in the membranes on water uptake, ion exchange capacity (IEC), proton conductivity, and methanol permeability were measured, respectively, via gravimetry, titration, impedance analysis, and gas chromatography techniques. The IEC values remained constant for all concentrations. Water uptakes and proton conductivities of the nanocomposite membranes changed with the clay content in a nonlinear fashion. While all the nanocomposite membranes had lower methanol permeability than Nafion 115 , the $6 \%$ concentration of Cloisite $93 \mathrm{~A}$ in sulfonated poly(vinyl alcohol) membrane displayed the greatest proton conductivity to methanol permeability ratio.
\end{abstract}

\section{Introduction}

Fuel cells are a type of electrochemical device that converts chemical to electrical signals and are used in many of today's applications including hybrid vehicles, laptop and cell phone batteries, and GPS systems. Because of their greater efficiency than combustion engines and the high possibility of zero-emissions in generating electricity, there has been a considerable interest to advance the development of fuel cells. A direct methanol fuel cell (DMFC), a type of proton exchange membrane fuel cell (PEMFC) (Figure 1), produces electricity through the direct addition of methanol liquid $\left(\mathrm{CH}_{3} \mathrm{OH}\right)$ at the anode. Methanol splits into protons that are transferred through the electrolyte polymeric membrane and electrons that travel through an external circuit. Carbon dioxide is also produced as a byproduct. As protons become oxidized at the cathode with the combination of oxygen and electrons, water is released as another by-product, and consequently, energy is generated.
The most common electrolyte polymeric membrane used in proton exchange membrane fuel cells is Nafion, a perfluorinated polymer that contains sulfonic acid groups which are essential for the presence of $\mathrm{SO}_{3} \mathrm{H}$ operates as the proton exchange mechanism within the membrane. Nafion often serves as the membrane in PEMFCs because of its high proton conductivity and high thermal stability. However, for the DMFCs, resistance to methanol permeability of the Nafion membrane has yet to be improved. This might be achieved by developing Nafion composite membrane using zeolite [1-3] and/or mordenite [4] as fillers. Alternatively, some new electrolyte polymeric membranes are being developed to use as a replacement of the Nafionbased membrane in DMFC applications including sulfonated poly(etheretherketone) [5], poly(vinylidene fluoride)-graftsulfonated polystyrene (PVDF- $g$-SPS) [6], sulfonated polysulfone [7], and sulfonated poly(vinyl alcohol) (PVA) [8]. The sulfonated PVA membrane is of high interest to use for DMFCs due to its relatively low cost and its inherent 


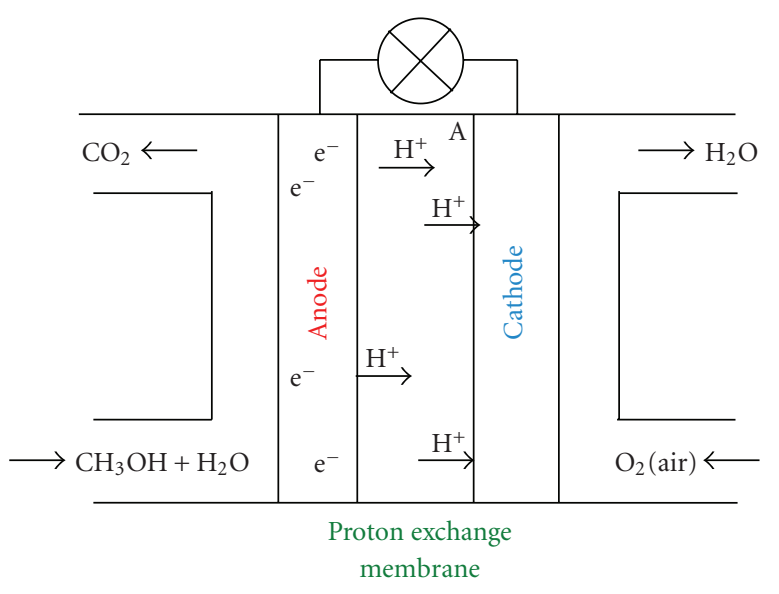

FIGURE 1: Schematic diagram illustrating the operating principle of a direct methanol fuel cell (DMFC).

properties of low methanol permeability as the PVA membrane has been previously used to separate alcohol from water through pervaporization [9]. Although the PVA membrane lack of proton conductivity, such a problem may be edited through the sulfonation process [10]. Sulfonating agents, some that could also serve as crosslinking agents, include sulfoacetic acid, 4-sulfophthalic acid, poly(acrylic acid), and sulfosuccinic acid. In this experiment sulfosuccinic acid is used as both the sulfonating and crosslinking agent for the PVA membrane.

Yet, earlier studies suggest that methanol permeability of sulfonated PVA membranes could have been further reduced [11]. To do so, nanofillers such as layered silicates may be added into the membrane to improve the properties of the nanocomposite membranes. The effects of adding layered silicate nanoclay have been researched, showing that methanol crossover through the electrolyte membrane decreased by the addition of about 1-2\% sodium montmorillonite (CloisiteNa) nanoclay with respect to Nafion membranes $[12,13]$. Noteworthy, besides the CloisiteNa nanoclay which is a kind of an unmodified layer silicate, many other types of organically modified nanoclays are available and their effects upon the performance of the electrolyte polymeric membranes have yet to be investigated.

In this study, rather than using the unmodified nanoclay, sulfonated PVA-layered silicate nanocomposite membranes with the addition of a commercially available organoclay, namely, Cloisite 93A are of interest. The objective is to investigate the effects of the organoclay content on water uptake, ion exchange capacity, proton conductivity, and methanol permeability of the membranes.

\section{Experiment}

2.1. Materials. Sulfosuccinic acid (70\% solution) was purchased from Aldrich (Steinheim, Germany). Montmorillonite nanoclay Cloisite 93A was obtained from Southern Clay Products (Gonzales, TX). Sodium hydroxide (analytical-reagent grade) was obtained from LabScan (Gliwice, Poland), sodium chloride (analytical-reagent grade) from
Carlo Erba Reagentic (Rodano, Italy), and methanol (analytical-reagent grade) from Fisher (Loughboroug, UK). All of the above chemicals were used as received. Sulfonated poly(vinyl alcohol) was prepared by carrying out a sulfonation of poly(vinyl alcohol) (PVA) ( $88 \%$ hydrolysis, $M_{w}=$ $72,000 \mathrm{~g} / \mathrm{mol}$, Buchs, Switzerland), using sulfosuccinic acid which serves as both a sulfonating agent and a cross-linking agent.

2.2. Sulfonation of PVA. Firstly, $10 \%$ aqueous solution of the PVA was prepared and refluxed at $90^{\circ} \mathrm{C}$ for six hours. Simultaneously nanoclay Cloisite $93 \mathrm{~A}(0 \%, 2 \%, 4 \%, 6 \%, 8 \%$ wt.) was dissolved in deionized water at room temperature for one hour. After mixing and stirring the two components together to achieve a homogenous solution, $20 \%$ by wt. of sulfosuccinic acid was added and then stirred at room temperature for 24 hours. To follow some changes in chemical structure of the polymer product after the sulfonation, a fourier transform infrared spectroscopy (FTIR) may be used. More details concerning characterizations of the sulfonated PVA have been previously demonstrated and those can be found in our earlier report [13].

2.3. Membrane Preparation. Once the sulfonation of PVAlayered silicate nanocomposite was finished, the solution was casted onto acrylic sheets. The casted membranes were first allowed to dry at $60^{\circ} \mathrm{C}$ until constant weight and then cured at $120^{\circ} \mathrm{C}$ for one hour to complete the sulfonation and crosslinking reactions. Afterwards, the cured membranes were peeled off from the acrylic plates, rinsed in deionized water to remove residual acid, and then stored in deionized water to test other properties of the polymeric membranes.

2.4. $X R D$. Intercalation and exfoliation of the nanoclay in the PVA membrane were investigated with an X-ray diffraction (XRD) technique with a D8 Discover diffractometer from Bruker (Madison, WI) Axis. The operation was in the $\theta-\theta$ geometry. The instrument used radiation from a copper target tube $\left(\mathrm{Cu} K_{\alpha}\right.$ radiation wavelength $\left.=1.541 \AA\right)$. The XRD data were collected between 2 and $60^{\circ}$ in steps of $0.02^{\circ}$ with an X-ray generator.

2.5. Water Uptake. Water uptake of the sulfonated PVA nanocomposite membranes was measured by first obtaining the dry weights of the membranes. After the membranes had been immersed in deionized water for 24 hours at room temperature and wiped with tissue paper, another weight measurement was immediately taken. Water uptake was calculated with the following:

$$
W(\%)=\left[\frac{\left(W_{\text {wet }}-W_{\text {dry }}\right)}{W_{\text {dry }}}\right] \times 100
$$

in which $W$ is water uptake measured as a percentage, $W_{\text {wet }}$ is the wet weight of the membranes, and $W_{\text {dry }}$ is the dry weight of the membranes. 
2.6. Ion Exchange Capacity. A titration technique was conducted to measure ion exchange capacity (IEC) of the membranes. Approximately $0.3-0.5 \mathrm{~g}$ of the sample was soaked in $0.1 \mathrm{M} \mathrm{NaCl}$ solution for 24 hours to allow the exchange of protons and sodium ions. Afterwards, a titration was performed using $0.1 \mathrm{M} \mathrm{NaOH}$ aqueous solution with phenolphthalein as the indicator to evaluate the amount of ions generated from the exchange process. IEC was calculated with the following:

$$
\mathrm{IEC}=\frac{m_{\mathrm{NaOH}}}{W_{\mathrm{dry}}}
$$

in which $m_{\mathrm{NaOH}}$ is the moles equivalent of $\mathrm{NaOH}$ and $W_{\text {dry }}$ is the dry weight of the membrane.

2.7. Proton Conductivity. Proton conductivities of the composite-sulfonated PVA membranes were measured by using a four-point probe technique. The impedance of the membrane was measured using an impedance analyzer (Autolab, PGSTAT 30) at a frequency of $10 \mathrm{kHz}$. The membrane was cut into a $3 \times 3 \mathrm{~cm}^{2}$ square and immersed in the deionized water for 12 hours, prior to measurement. The hydrated membrane was mounted onto the cell and an AC current of $0.35 \mathrm{~mA}$ was applied to the cell. The conductance of the sample was obtained from the AC potential difference between the two inner electrodes. The conductivity $(s)$ was calculated by using the following:

$$
\sigma=\frac{l}{R S}
$$

where $\sigma$ is the proton conductivity $(\mathrm{S} / \mathrm{cm}), R$ is the bulk resistance of the membrane, $S$ is the cross-sectional area of the membrane $\left(\mathrm{cm}^{2}\right)$, and $l$ is the distance between the counter electrode and the working electrode $(\mathrm{cm})$.

2.8. Methanol Permeability. Methanol permeability which is related to the membranes' resistances to methanol crossover was measured by setting up a two identical compartment glass cell to serve as a diffusion cell. The composite membrane was placed in between the two compartments and securely clamped. $30 \mathrm{~mL}$ of methanol solution $(2.0 \mathrm{M})$ and $30 \mathrm{~mL}$ of deionized water were respectively, added to compartments A and B. After the setup, both compartments were magnetically stirred at room temperature for 100 minutes with a $2 \mathrm{~mL}$ sample drawn out from compartment $\mathrm{B}$ every 20 minutes. These samples were then used to measure the concentration of methanol in compartment $\mathrm{B}$ as a function of diffusion time by using gas chromatography (GC) (Shimadzu GC-9A, containing BX-10 column, Haverhill, MA) with an injection temperature of $120^{\circ} \mathrm{C}$, column temperature of $85^{\circ} \mathrm{C}$, and detection temperature of $150^{\circ} \mathrm{C}$. The area under the methanol peak from each GC chromatogram was combined with a calibration curve to evaluate the methanol concentration. Methanol permeability was then calculated from the following:

$$
P=\frac{V_{\mathrm{B}} \times L \times d C_{\mathrm{B}} / d t}{C_{\mathrm{A}} \times A},
$$

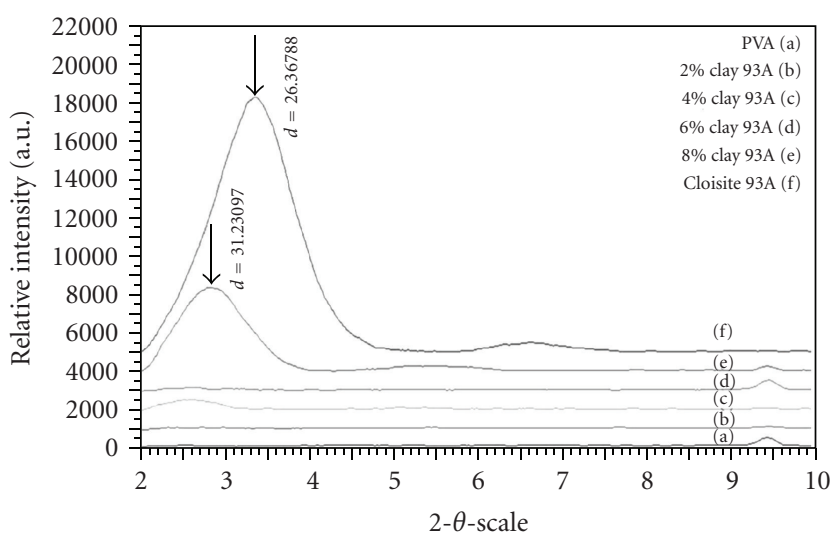

FIGURE 2: XRD patterns of sulfonated PVA membranes varying in concentration of Cloisite 93A.

in which $P$ is methanol permeability $\left(\mathrm{cm}^{2} / \mathrm{s}\right), V_{\mathrm{B}}$ is the volume of deionized water $\left(\mathrm{cm}^{3}\right), L$ is the thickness of the membrane $(\mathrm{cm}), A$ is the area of the membrane $\left(\mathrm{cm}^{2}\right), C_{\mathrm{A}}$ and $C_{B}$ are concentrations of methanol in compartments $A$ and $\mathrm{B}$, respectively, and $\left(d C_{\mathrm{B}}\right) / d t$ is the slope of the methanol concentration (\%) over diffusion time (s).

\section{Results and Discussion}

3.1. Characterization of the Modified Membranes. An XRD analysis of the modified sulfonated membranes, along with pure Cloisite 93A and pure PVA, is shown in Figure 2. The XRD pattern of pure Cloisite 93A contains a peak at $2 \theta=3.4^{\circ}$ corresponding to a basal spacing of $2.03 \mathrm{~nm}$. When $8 \%$ of the clay was added to the PVA, XRD pattern of the composite membrane shows a peak at $2 \theta=2.8^{\circ}$. This can be translated to the clay basal spacing of $3.12 \mathrm{~nm}$. Of note, this peak has been shifted to a lower $2 \theta$ angle, suggesting that a basal spacing between layers of the clay has been increased. In other words, the above result implies that the Cloisite 93A layer silicates are intercalated within the PVA matrix. Furthermore, XRD peak of the composite membrane containing $4 \%$ clay shifted to a lower angle $\left(2 \theta=2.6^{\circ}\right)$. Intensity of the peak is also decreased as compared to that in the former case, suggesting that the layer silicates are partly intercalated and exfoliated within the polymer matrix. Of note, for the membranes containing $2 \%$ and $6 \%$ clay, the characteristic XRD peak of the clay cannot be seen. It is apparently that there was no layer silicate exists at the particular spot during the XRD analysis. It might be possible that the clays are exfoliated in the nanocomposite membranes. However, additional evidences from other technique such as TEM should be considered to support the above XRD results.

3.2. Water Uptake and Ion Exchange Capacity of the Membranes. Figure 3 shows the effects of Cloisite 93A content on water uptake. The water uptake initially decreases with the addition of $2-4 \%$ nanoclay. However, as the amount of nanoclay increases even more, to $6 \%$, the water uptake value 
increased. The similar nonlinear trend was also observed for the sulfonated PVA membranes containing CloisiteNa [13]. These effects were described in the light of a difference in water affinity between the clay and the sulfonated polymer. In addition, polar-polar interaction between the polymer and the layer silicate could also be taken into account. These factors tend to limit polymer chain mobility and diffusibility of water molecules into the membrane, and ultimately decreasing water uptake. On the other hand, degree of crystallinity of the polymer might decrease when the sufficient amount of organoclay was presence. As a result, there are more free volume for the water to diffuse into and thus increasing water uptake of the membrane. As the amount of Cloisite 93A increase to $8 \%$, a slight decrease in water uptake was observed again. At this stage, some of the nanoclay might be aggregated and interferes with decreasing the crystallinity-thus explaining the higher water uptake of $8 \%$ than those of $2 \%$ and $4 \%$ but lower than $6 \%$ membrane. By comparing water uptake values of the PVA/Cloisite 93A membranes in this study to those of the PVA/CloisiteNa membranes [13], it was found that the uptake values of the former membrane system are higher than that of latter membrane system, provided the same clay content. For example, water uptake of the composite membranes containing $2 \%$ and $4 \%$ CloisiteNa are 30 and $36 \%$, respectively [13]. The differences could be related to a greater hydrophilicity of the CloisiteNa, which promote a stronger polar interaction between the polymer and the clay. Consequently, diffusibility of water molecules into the PVA/CloisiteNa membranes is lower.

Figure 4 shows the IEC values of the sulfonated PVA nanocomposite membranes. It can be seen that the IEC generally remained constant with the different concentrations of Cloisite 93A with standard deviation values taken into account. Such results may be due to the constant amount of sulfosuccinic acid used for a sulfonation of each membrane, regardless of the concentration of nanoclay. These IEC values are, however, lower than the reported value of Nafion 115 membrane, which is approximately $0.91 \mathrm{mmol} / \mathrm{g}$ [14]. The difference might be due to the discrepancy in degree sulfonation between the two membrane systems.

\subsection{Proton Conductivity and Methanol Permeability. Figure 5} shows proton conductivity of the modified membranes. Again, it can be seen that the relationship between conductivity and the clay content was not in a linear fashion. The conductivity initially decreased with an addition of 2 to $4 \%$ of the organoclay. However, when the clay concentration was increased, the proton conductivity increases to the maximum value at $6 \%$ and then decreases again at $8 \%$ concentration. The above trend is analogue to the water uptake properties previously discussed. This similarity may be so since proton conductivity is directly related to water uptake; that is, water molecules serve as the vehicles to transfer protons through the membrane, and thus, the greater amount of water uptake, the greater the proton conductivity of the membrane for there are more vehicles to transport the protons. Noteworthy, proton conductivity of the PVA/Cloisite 93A membranes

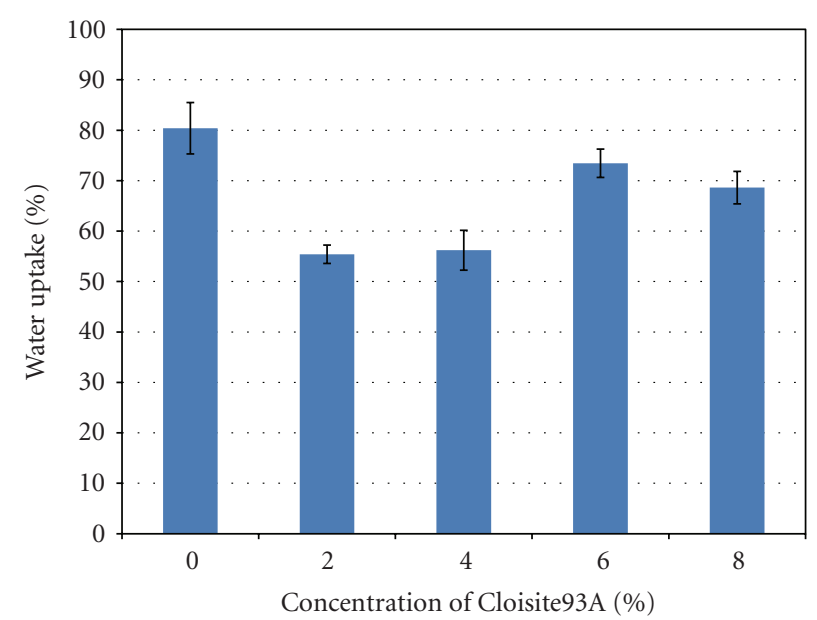

FiguRe 3: Water uptake values of sulfonated PVA membranes with varying concentrations of Cloisite 93A.

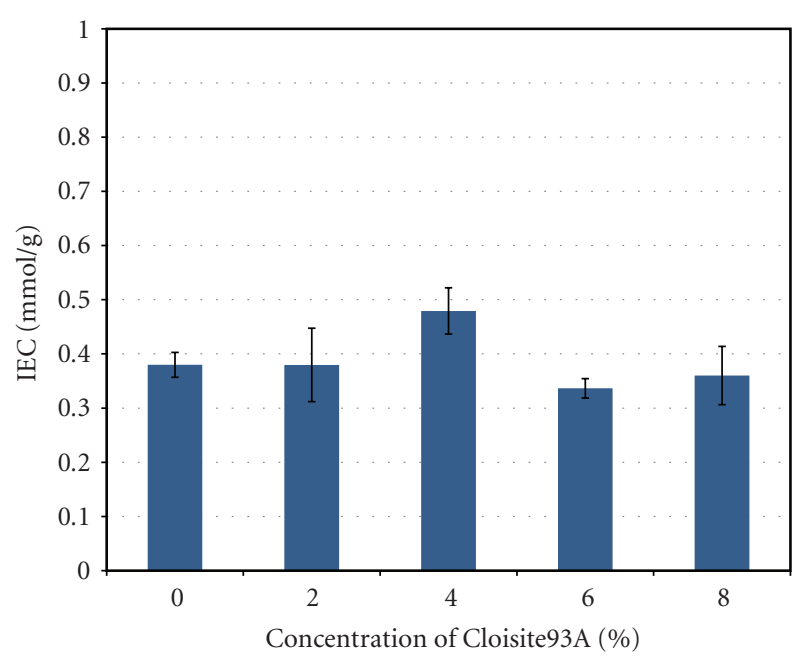

FIGURE 4: IEC values of sulfonated PVA membranes with varying concentrations of Cloisite 93A.

herein is slightly higher than that of the PVA composite membranes containing $2 \%$ and $4 \%$ CloisiteNa which are $8.5 \times 10^{-3} \mathrm{~S} / \mathrm{cm}$ and $10.0 \times 10^{-3} \mathrm{~S} / \mathrm{cm}$, respectively [13]. The differences could be attributed to the greater water uptake values of the former composite membranes system.

Figure 6 shows methanol permeability of the various PVA/Cloisite 93A composite membranes. In general, it can be seen that methanol permeability of the nanocomposite membranes is lower than that of the bare PVA membrane, regardless of the clay content. The effect is attributed to a steric hindrance effect provided by the presence of the nanoclay. The above statement was supported by results from the above XRD patterns (Figure 2) which suggested that some of the nanoclay has been intercalated and exfoliated. Of note, relationship between methanol permeability and clay content is nonlinear. The addition of the organoclay initially decreases the methanol permeability. However at 6 and $8 \%$ clay, the permeability increased. In this regard, changes in 


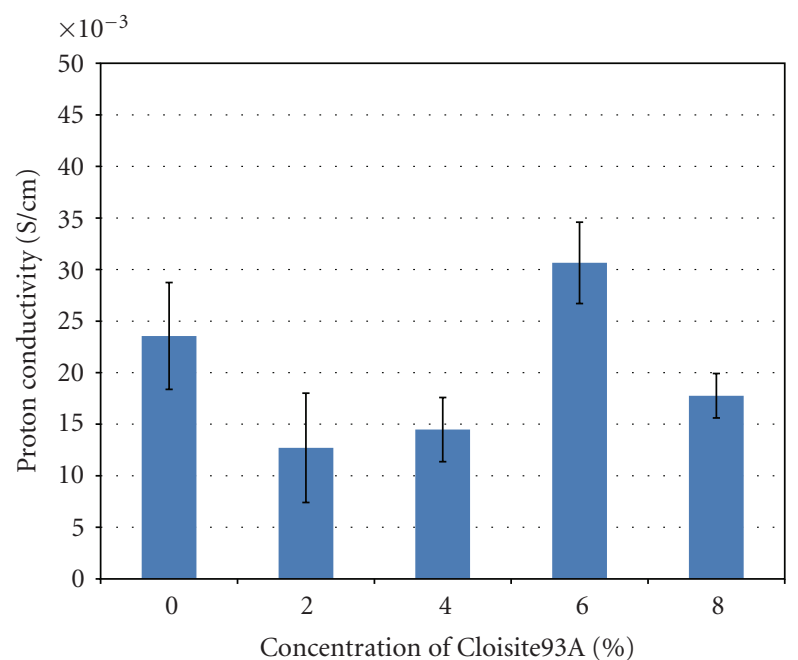

FIGURE 5: Proton conductivity values of sulfonated PVA membranes with varying concentrations of Cloisite 93A.

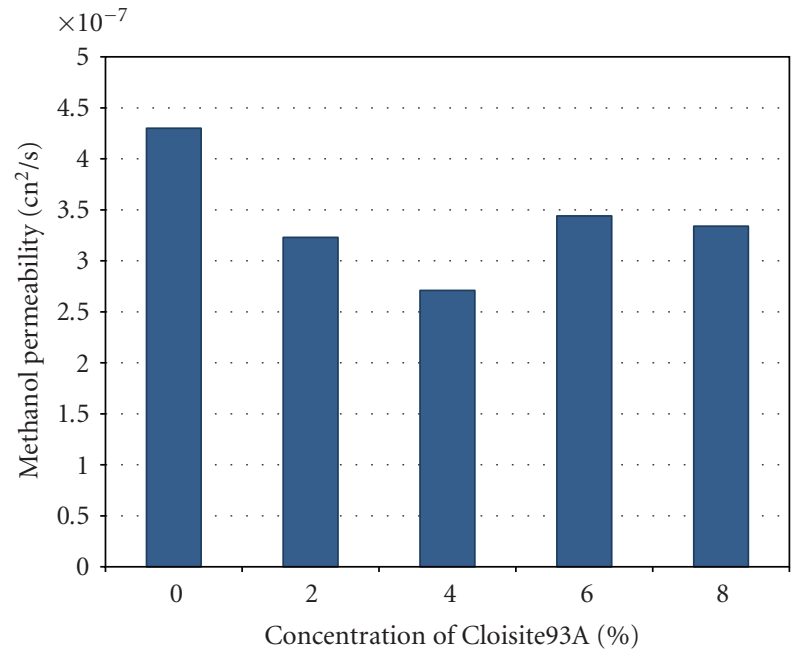

FIGURE 6: Methanol permeability values of sulfonated PVA membranes with varying concentrations of Cloisite 93A.

water uptake of the membranes with the clay content could also come into play. This was because in the experimentutilized methanol solution, the aqueous form accounts for greater methanol solubility in a higher water uptake environment. Water uptake of the composite membranes containing $6 \%$ and $8 \%$ clay is higher than that of the $2 \%$ and $4 \%$ clay; therefore, the greater methanol permeability could be expected. Interestingly, methanol permeability values of the PVA/Cloisite 93A membranes herein are higher than those of the PVA/CloisiteNa membranes containing the same amount of clay [13]. The above discrepancies can be attributed to the higher water uptake values and a better clay exfoliation of the latter membrane system.

Finally, the results of proton conductivity and methanol permeability are combined to yield the $\mathrm{C} / \mathrm{P}$ (conductivity/permeability) ratios of the developed DMFC membrane. Evaluating the $\mathrm{C} / \mathrm{P}$ ratio, the most effective membrane

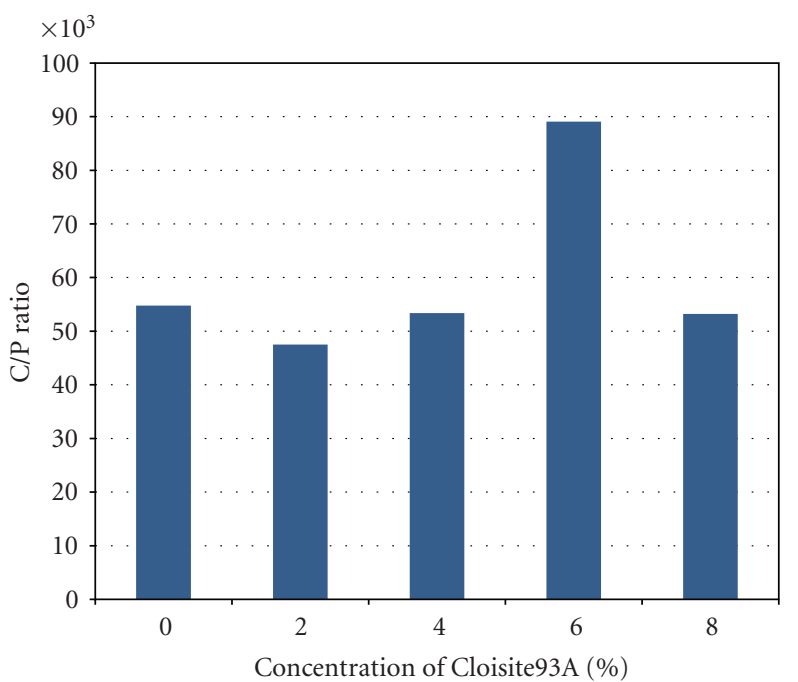

FIGURE 7: C/P ratios of sulfonated PVA membranes with varying concentrations of Cloisite 93A.

developed in this study would have the maximum ratiodisplaying the ability to transfer protons in an efficient manner with less methanol permeability to increase the efficiency of DMFC. Figure 7 displays that the maximum $\mathrm{C} / \mathrm{P}$ ratio lies within the $6 \%$ concentration of the organoclay Cloisite $93 \mathrm{~A}$ within the sulfonated membrane. For a comparison purpose, conductivity and permeability of the Nafion 115 membrane were determined by using the same techniques it was found that the $\mathrm{C} / \mathrm{P}$ ratio of the sulfonated PVA membrane containing $6 \%$ of Cloisite $93 \mathrm{~A}$ was $89.05 \times 10^{3}$ which is approximately three times greater than that of Nafion115 membrane $\left(29.49 \times 10^{3}\right)$.

Last but not least, by comparing with the previous work [13] based on the same membrane system-utilized CloisteNa clay, it was found that the maximum $\mathrm{C} / \mathrm{P}$ ratio could be obtained by using only $2 \%$ of the CloisiteNa layer silicate. The different optimum clay content suggests that the sulfonated PVA membrane is more compatible with the natural form nanoclay (CloisiteNa) than the organically modified clay (Cloisite 93A) used in this study. This could be ascribed to the fact that sulfonated PVA is highly polar containing both hydroxyl groups and sulfonic acid groups within the molecules.

\section{Conclusions}

The incorporation of the montmorillonite organoclay Cloisite 93A upon sulfonated PVA membranes strongly affected properties of the polymer membranes. Water uptake, proton conductivity, and methanol permeability of the membranes changed with the clay content in a nonlinear fashion. The optimum concentration of the organoclay Cloisite 93A within the sulfonated PVA membrane, corresponding to the maximum $\mathrm{C} / \mathrm{P}$ ratio, was $6 \%$. This $\mathrm{C} / \mathrm{P}$ ratio value is also higher than that of the commercial Nafion115 membrane, determined by using the same techniques in this study. 


\section{Acknowledgments}

Ms. Sanglimsuwan is sincerely grateful to the National Science Foundation (NSF) for sponsoring the International Research Experience for Undergraduates (IREU) program, allowing her to conduct research in Bangkok, Thailand, through the NSF Site-Grant no. DMR0754632. She would also like to thank the IREU Director Dr. Supapan Seraphin from the Department of Materials Science Engineering at the University of Arizona and IREU Coordinator Dr. Nandh Thavarungkul from the Division of Materials Technology at King Mongkut's University of Technology Thonburi (KMUTT).

\section{References}

[1] P. Staiti, A. S. Aricò, V. Baglio, F. Lufrano, E. Passalacqua, and V. Antonucci, "Hybrid Nafion-silica membranes doped with heteropolyacids for application in direct methanol fuel cells," Solid State Ionics, vol. 145, no. 1-4, pp. 101-107, 2001.

[2] X. Li, E. P. L. Roberts, S. M. Holmes, and V. Zholobenko, "Functionalized zeolite A-nafion composite membranes for direct methanol fuel cells," Solid State Ionics, vol. 178, no. 1920, pp. 1248-1255, 2007.

[3] E. N. Gribov, E. V. Parkhomchuk, I. M. Krivobokov, J. A. Darr, and A. G. Okunev, "Supercritical $\mathrm{CO}_{2}$ assisted synthesis of highly selective nafion-zeolite nanocomposite membranes for direct methanol fuel cells," Journal of Membrane Science, vol. 297, no. 1-2, pp. 1-4, 2007.

[4] Z. Chen, B. Holmberg, W. Li et al., "Nafion/zeolite nanocomposite membrane by in situ crystallization for a direct methanol fuel cell," Chemistry of Materials, vol. 18, no. 24, pp. 5669-5675, 2006.

[5] P. Xing, G. P. Robertson, M. D. Guiver, S. D. Mikhailenko, K. Wang, and S. Kaliaguine, "Synthesis and characterization of sulfonated poly(ether ether ketone) for proton exchange membranes," Journal of Membrane Science, vol. 229, no. 1-2, pp. 95-106, 2004.

[6] B. Soresi, E. Quartarone, P. Mustarelli, A. Magistris, and G. Chiodelli, "PVDF and P(VDF-HFP)-based proton exchange membranes," Solid State Ionics, vol. 166, pp. 383-389, 2004.

[7] F. Lufrano, V. Baglio, P. Staiti, A. S. Arico', and V. Antonucci, "Development and characterization of sulfonated polysulfone membranes for direct methanol fuel cells," Desalination, vol. 199, no. 1-3, pp. 283-285, 2006.

[8] D. S. Kim, H. B. Park, J. W. Rhim, and Y. M. Lee, "Preparation and characterization of crosslinked $\mathrm{PVA} / \mathrm{SiO}_{2}$ hybrid membranes containing sulfonic acid groups for direct methanol fuel cell applications," Journal of Membrane Science, vol. 240, no. 1-2, pp. 37-48, 2004.

[9] B. S. Pivovar, Y. Wang, and E. L. Cussler, "Pervaporation membranes in direct methanol fuel cells," Journal of Membrane Science, vol. 154, no. 2, pp. 155-162, 1999.

[10] J. W. Rhim, H. B. Park, C. S. Lee, J. H. Jun, D. S. Kim, and Y. M. Lee, "Crosslinked poly(vinyl alcohol) membranes containing sulfonic acid group: proton and methanol transport through membranes," Journal of Membrane Science, vol. 238, no. 1-2, pp. 143-151, 2004.

[11] N. Seeponkai and J. Wootthikanokkhan, "Proton conductivity and methanol permeability of sulfonated poly(vinyl alcohol) membranes modified by using sulfoacetic acid and poly(acrylic acid)," Journal of Applied Polymer Science, vol. 105, no. 2, pp. 838-845, 2007.

[12] M. K. Song, S. B. Park, H. K. Kim, S. K. Min, and H. W. Rhee, "Characterization of polymer-layered silicate nanocomposite membranes for direct methanol fuel cells," Electrochimica Acta, vol. 50, no. 2-3, pp. 639-643, 2004.

[13] P. Duangkaew and J. Wootthikanokkhan, "Methanol permeability and proton conductivity of direct methanol fuel cell membranes based on sulfonated poly(vinyl alcohol)-layered silicate nanocomposites," Journal of Applied Polymer Science, vol. 109, no. 1, pp. 452-458, 2008.

[14] C. W. Lin, R. Thangamuthu, and C. J. Yang, "Protonconducting membranes with high selectivity from phosphotungstic acid-doped poly(vinyl alcohol) for DMFC applications," Journal of Membrane Science, vol. 253, no. 1-2, pp. 2331, 2005. 


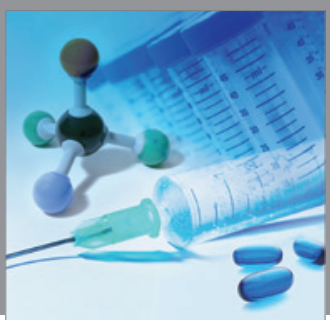

International Journal of

Medicinal Chemistry

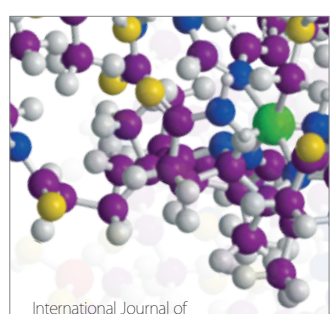

Carbohydrate Chemistry

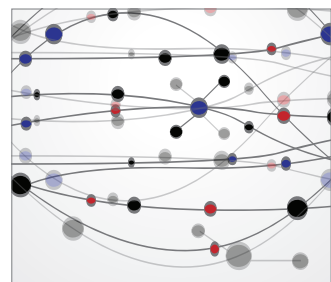

The Scientific World Journal
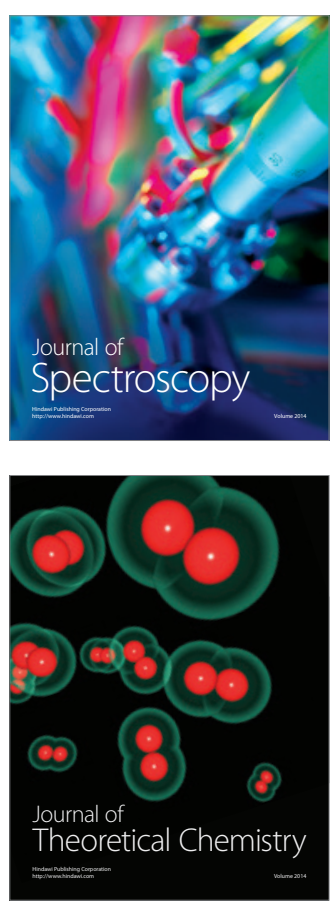
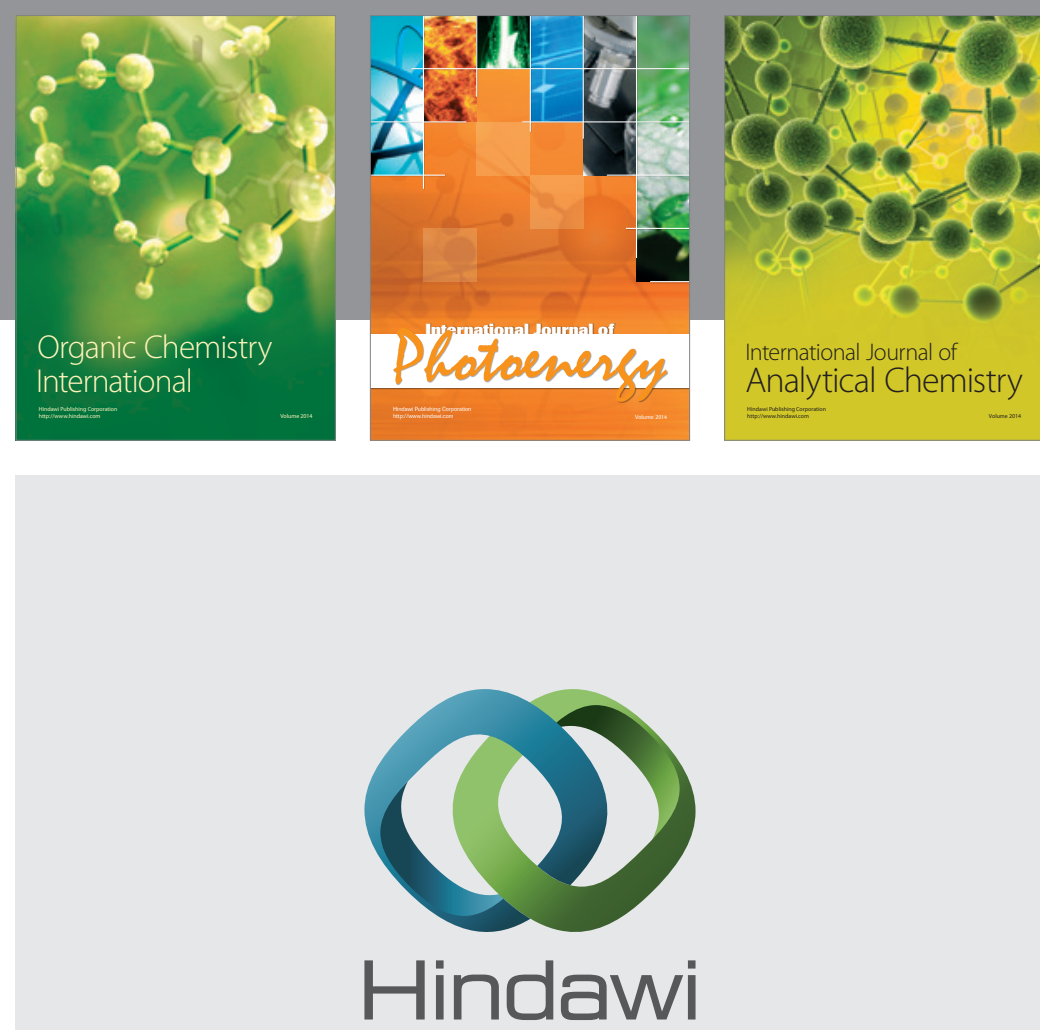

Submit your manuscripts at

http://www.hindawi.com
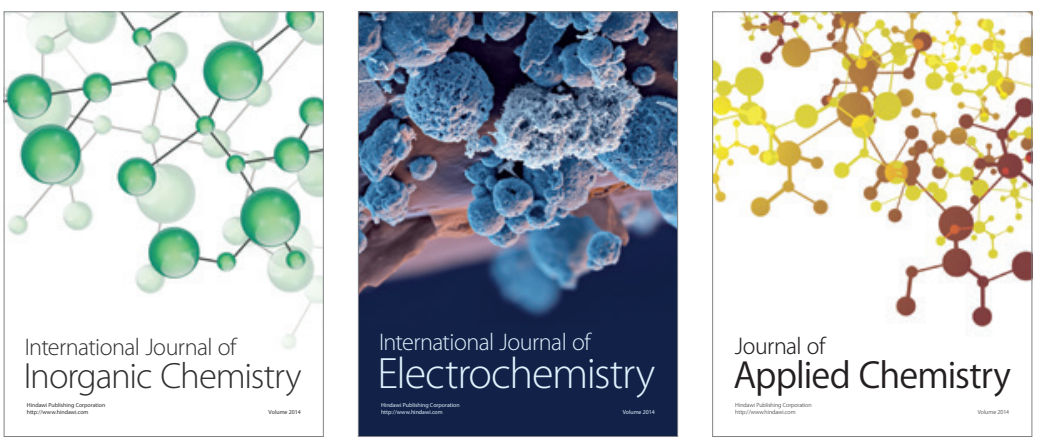

Journal of

Applied Chemistry
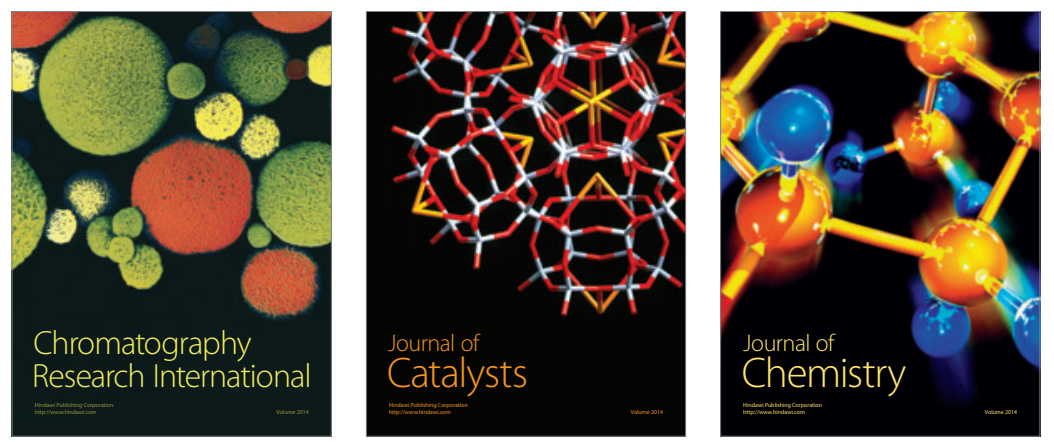
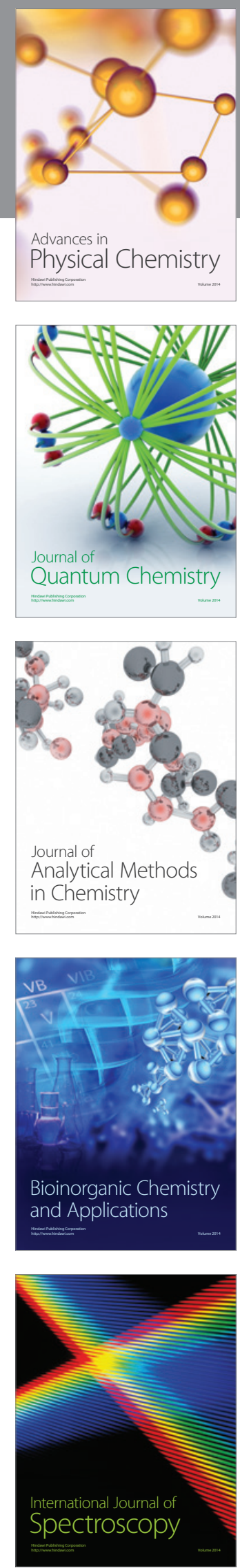